\title{
Nieznany wiersz Adama Mickiewicza? Rękopis tekstów poetyckich z pierwszej połowy XIX wieku w Bibliotece Poznańskiego Towarzystwa Przyjaciół Nauk. Komunikat
}

Czy w dzisiejszych czasach mogą nas jeszcze spotkać niespodzianki w dziedzinie tak dokładnie poznanej, jak twórczość Adama Mickiewicza? Okazuje się, że odnalezione nowe źrodła mogą prowadzić do kolejnych ustaleń na temat poezji wieszcza.

Do Biblioteki Poznańskiego Towarzystwa Przyjaciół Nauk trafił niedawno drogą depozytu dra Norberta Zawiszy rękopis „Teksty poetyckie z 1 połowy XIX w.”, który w Bibliotece PTPN otrzymał sygnaturę rkp 2112. Zapisano w nim kilkadziesiąt utworów o tematyce patriotycznej. Zeszyt ten pozornie wygląda jak wiele innych zbiorków poezji spisywanych przez polskich patriotów w okresie zaborów. Jednak dokładniejsza analiza treści owego rękopisu zdradza, że tym razem mamy do czynienia z czymś więcej, niż tylko ze zwykłym odpisem wydrukowanych wcześniej utworów.

Większość wierszy zamieszczonych w rękopisie 2112 ogłoszono drukiem przed wpisaniem do zeszytu, jak np. Krystyn Szykowski i Pomnik w Hodowie Jana Kantego Podoleckiego (poz. 13 a-b spisu - zob. niżej) oraz Aniot i dziewczyna i Nowy rok 1845 Teofila Lenartowicza (poz. 9 a-b). Mogły więc zostać przepisane z wersji drukowanej. Pierwodruki innych utworów, np. Do Eryka Jachowicza Narcyzy Żmichowskiej (poz. 26) i Kradzione. Przypowieść szlachecka (podstuchano) Władysława Syrokomli (poz. 18), wydano po roku 1849. Widocznie przepisujący korzystali z innych odpisów zanotowanych przez siebie wierszy. Odnośnie do kilku utworów, między innymi Gustawa Ehrenberga „Damy naszych salonów” (poz. 2) i T.[?] „Moje wspomnienie z 1837 r." (poz. 19), nie udało się na aktualnym etapie badań ustalić, czy i gdzie zostały opublikowane. Wydrukowano też czterowers zatytułowany W albumie księcia Golicyna, który w poznańskim rękopisie stanowi fragment większej całości, 
zaczynającej się od słów „Powiedz czy język polskiego narodu” (poz. 11) - całość tę przytaczam w niniejszym komunikacie. Fragment opublikowano jako utwór Mickiewicza.

Powstaje pytanie: czy możliwe, aby $\mathrm{w}$ zeszycie $\mathrm{z}$ połowy XIX w. zachowała się nieznana wersja utworu Mickiewicza? Odpowiedź może dać dopiero dokładna analiza zamieszczonego w nim wiersza, a także samego rękopisu.

Jest to zeszyt o rozmiarach $25 \mathrm{~cm}$ x $20 \mathrm{~cm}$ i 120 kartach spisany w latach 1848-1849 prawdopodobnie na terenie zaboru rosyjskiego. Świadczyłaby o tym adnotacja na wewnętrznej tylnej okładzinie zawierająca datę 21 czerwca/3 lipca 1848 r. (zapisaną według podwójnego kalendarza: gregoriańskiego i juliańskiego) oraz kolejne wpisywane daty. Rękopis nie ma jednego autora wiersze wpisywało kilka osób, co potwierdzają różne charaktery pisma. Również okładka nie pozwala na ustalenie autorów czy właścicieli: grzbiet półskórkowej oprawy został zdarty, podobnie jak nalepka na przedniej okładzinie. Pozostały po nich tylko ślady.

Rękopis rozpoczyna patriotyczny wiersz Hymn ortów Edmunda Wasilewskiego. Utwór ten był wcześniej publikowany w „Tygodniku Literackim” (1839, nr 36). Odpisujący tekst wiersza nie podał pełnego nazwiska autora, jedynie jego inicjały. Podobnie postąpił też $\mathrm{w}$ przypadku innych przytoczonych tekstów krakowskiego poety, których patriotyczny charakter był źle widziany przez rosyjskiego zaborcę.

Niżej podaję spis tekstów zawartych w rękopisie, w kolejności alfabetycznej według nazwisk autorów, $\mathrm{z}$ adnotacjami dotyczącymi pierwodruków każdego z utworów ${ }^{\mathrm{I}}$. Schemat ten przyjęłam ze względu na to, że wiersze poszczególnych poetów (jak np. 12 utworów Wasilewskiego) nie są zamieszczone po kolei, lecz w różnych częściach zeszytu.

1. [Chodźko Michał]: „Obraz dobrej kobiety” k. 56. Pierwodruk: M. Chodźko, Dziesięć obrazów z wyprawy do Polski, Paryż 1841 , s. $143-144$.

2. [Ehrenberg] Gustaw: [„Improwizacya”?], fragment, inc.: „Damy naszych salonów” k. 44.

3. Goethe Johann Wolfgang: „Faust”, fragmenty, tłum. Włodzimierz Wolski, k. 48v-56. Pierwodruk: „Biblioteka Warszawska” 1848, t. 3.

4. Gorecki Antoni: „Śmierć zdrajcy ojczyzny” k. 102v-104. Pierwodruk: „Tygodnik Polski” 1818.

${ }^{\text {I }}$ Informacje zawarte w nawiasach kwadratowych - niepodane w rękopisie 2112 - pochodzą od autorki artykułu. 
5. Jaśkowski Jan Nepomucen:

a. „Ballada, jakich wiele” k. 92-94. Pierwodruk: „Przyjaciel Ludu” 1838, nr 21.

b. „Do poetów” k. 1-2. Pierwodruk: „Tygodnik Literacki” $1839, \mathrm{nr} 4$.

6. Komierowski Józef: „Krzyż”, Sielc 8.11.[18]44, k. 39. Pierwodruk: „Przegląd Naukowy” 1845, nr 9 [tam autorem „J.”].

7. Körner [Karl Theodor]: „Modlitwa przed bitwą”, [thum. Franciszek Kowalski], k. 20. Pierwodruk jako pieśń, Warszawa 1831.

8. [Krasiński Zygmunt]: „Irydion”, fragment k. 20v-23. Pierwodruk: Paryż 1836.

9. Lenartowicz [Teofil]:

a. „Anioł i dziewczyna” k. 43. Pierwodruk: Album warszawskie, Warszawa 1845.

b. „Nowy rok 1845” k. 41. Pierwodruk: „Przegląd Naukowy” $1845, \mathrm{nr} 1$.

10. M.G. [Maurycy Gosławski?], wiersz, inc.: „Dwa są życia, dwa są światy" k. 19v-20, Stanisławów 1833.

11. [Mickiewicz Adam], inc.: „Powiedz czy język polskiego narodu...” k. 102. Wersja dwunastowersowa. Ostatnia zwrotka drukowana pod tytułem W albumie księcia Golicyna w: Kraków-Zagrzebiowi, Kraków 1881.

12. N[iewiarowski?] Aleksander: [Recenzja utworów Ludwika Sztyrmera] k. 40. Pierwodruk: „Przegląd Naukowy” 1845, nr 3.

13. Podolecki J[an] K[anty]:

a. „Krystyn Szykowski” k. 60-61. Pierwodruk: Album na korzyść pogorzelcówe, Lwów 1844.

b. „Pomnik w Hodowie” k. 61-62. Pierwodruk: Album na korzyść pogorzelców, Lwów 1844.

14. Pol W[incenty]: „Gawęda przy miodzie” k. 94v-100.

15. Prusinowski Jan: „Sława” k. 101-102.

16. Puszkin Aleksander: „Cyganie”, thum. Leon Janiszewski, Tyflis 1842, k. 24-38. Pierwodruk: „Biblioteka Warszawska” 1842, t. 2.

17. Schlegel Wilhelm, inc.: „L'éducation faite en s'amusant..."k. 56v-58.

18. Syrokomla Władysław (Ludwik Kondratowicz): „Kradzione. Przypowieść szlachecka (podsłuchano)", 12.3.1849, k. 58-60. Pierwodruk: Gawędy i rymy ulotne. (Poczet 1), Warszawa 1853.

19. T.[?]: „Moje wspomnienie z r. 1837” k. 43v.

20. Vernier Jean-Napoléon: „La Croix des Champs” k. 8-9. 
21. W[asilewski] E[dmund]:

a. „Co mi tam!” k. 10v-11. Pierwodruk: E. Wasilewski, Poezje, Kraków 1849, s. 205-206.

b. „Do gwiazdy” k. 11-12. Pierwodruk: E. Wasilewski, Poezje, Kraków 1849, s. 229-231.

c. „Hymn orłów” k. 1. Pierwodruk: „Tygodnik Literacki” $1839, \mathrm{nr} 36$.

d. „Improwizacja wariata” k. 16-18. Pierwodruk: E. Wasilewski, Poezje, Kraków 1849, s. 234-238.

e. „Marii S. na pamiątkę” k. 18-19. Pierwodruk: E. Wasilewski, Poezje, Kraków 1849, s. 253-256.

f. „Marzenie po balu” k. 12. Pierwodruk: E. Wasilewski, Poezje, Kraków 1849, s. 248-249.

g. „Odpowiedź” k. 2-3. Pierwodruk jako Odpoetów. Odpowied $z^{\prime}$,Tygodnik Literacki” 1839, nr 10.

h. „Pieśń” k. 15-16. Pierwodruk jako Pieśn wygnańca: E. Wasilewski, Poezje, Kraków 1849, s. 250-252.

i. „Pragnienie cudu” k. 9-10. Pierwodruk: E. Wasilewski, Poezje, Kraków 1849, s. 199-202.

j. „Skargi drzew” k. 3-5. Pierwodruk: E. Wasilewski, Poezje t. 1, Poznań 1840, s. 43-52.

k. „Ułamki poematu Krakowiaki” k. 6-8. Pierwodruk: „Tygodnik Literacki” 1839, nr 21.

1. „Wieści o wiośnie” k. 12v-15. Pierwodruk jako Wieści o wiośnie. (Fantazja): „Tygodnik Literacki” 1840, nr 7.

22. Wolski Włodzimierz:

a. „Fantazja wieczorna” k. 48. Pierwodruk: „Przegląd Naukowy" 1843 , t. 2, nr 11.

b. „Liszt - fantazja” k. 45-46. Pierwodruk: tamże.

c. „Pół światła, pół cienia” k. 43v-44. Pierwodruk: „Dzwon Literacki” 1846, t. 1.

23. „Wyprawa Igora na Połowców, poemat sławiański”, wyd. Augustyn Bielowski, Lwów 1833, k. 63-91.

24. Zieliński: „Do mojej gwiazdki” k. 20v.

25. Zmorski Roman: „Franciszkowi Liszt” k. 46v-47. Pierwodruk: „Przegląd Naukowy” 1843, t. 2, nr 11.

26. [Żmichowska Narcyza] Gabryella: „Do Eryka Jachowicza” k. 105-111. Pierwodruk jako Dziedzictwo Eryka w: Listy Narcyzy Żmichowskiej do rodziny i przyjaciót, t. 2, Kraków 1885, s. $604-612$.

27. Żochowski Feliks: „Mowa jest skutkiem usiłowań człowieka" k. 41v.

28. NN: Wiersz, inc.: „Młodzieńcze co niepewne jeszcze wiedziesz kroki” k. 44v-45. 
Ponadto różne drobne cytaty $\mathrm{z}$ pisarzy francuskich i niemieckich (V. Hugo, G. Sand, H. Balzac, A. Dumas, F. Schiller) k. $119 \mathrm{v}-120 \mathrm{v}$.

Jak wynika ze spisu, zbiór zawiera kilkadziesiąt różnych tekstów pochodzących z okresu romantyzmu, głównie o tematyce patriotycznej. Jednak najbardziej intryguje wiersz zapisany na kartach 102-102v rękopisu (poz. 11):

Powiedz czy język Polskiego narodu

Czy wolną duszę podobałeś?

Powiedz? bo niewiem[!] z jakiego powodu

Bym tu słów kilka napisał, chciałeś?

Gdy ci się wydał dźwięk języka miły

Dźwięk dusz harmonii więcej cię poruszy.

Wyrazy Polskie twe ucho bawily

Lecz dusze wolne przemówią do duszy.

Jeśli znasz wolność i cenić ją umiesz,

$\mathrm{W}$ rozmowie naszej niepotrzebne słowa,

Ja Twe westchnienie, ty mą łzę zrozumiesz

I dłoń mi ściśniesz! To jest polska mowa.

Utwór został zanotowany wśród innych tekstów poetyckich w 1849 r. Nie podano ani jego tytułu, ani nazwiska autora. Przypuszczalnie autor był znany przepisującemu, a jednocześnie zakazany w zaborze rosyjskim. Porównanie wiersza z tekstami drukowanymi wykazuje, że cztery ostatnie wersy utworu przypisywane są Adamowi Mickiewiczowi. Ostatnia zwrotka, z pewnymi zmianami, była opublikowana pod tytułem $W$ albumie księcia Golicyna, jednak dopiero w 1881 r. w albumie Kraków Zagrzebiowi. Czterowiersz został spopularyzowany w XX w., gdy muzyk kompozytor Witold Friemann (1889-1977) ułożył do jego słów melodię. Natomiast wersja 12 -wersowa zachowana w rękopisie 2112 z Biblioteki PTPN nie jest znana z innych źródeł²

${ }^{2}$ Czy rzeczywiście zacytowane trzy zwrotki, zanotowane jeszcze za życia Adama Mickiewicza, to utwór wieszcza? Można się spodziewać, że odpowiedź na to pytanie dadzą badania podjęte ostatnio przez dr Zofię Dambek z Instytutu Filologii Polskiej UAM w Poznaniu. Wszystkie fotografie zamieszczone w artykule wykonał dr Arkadiusz Wagner, dyrektor Biblioteki PTPN. 


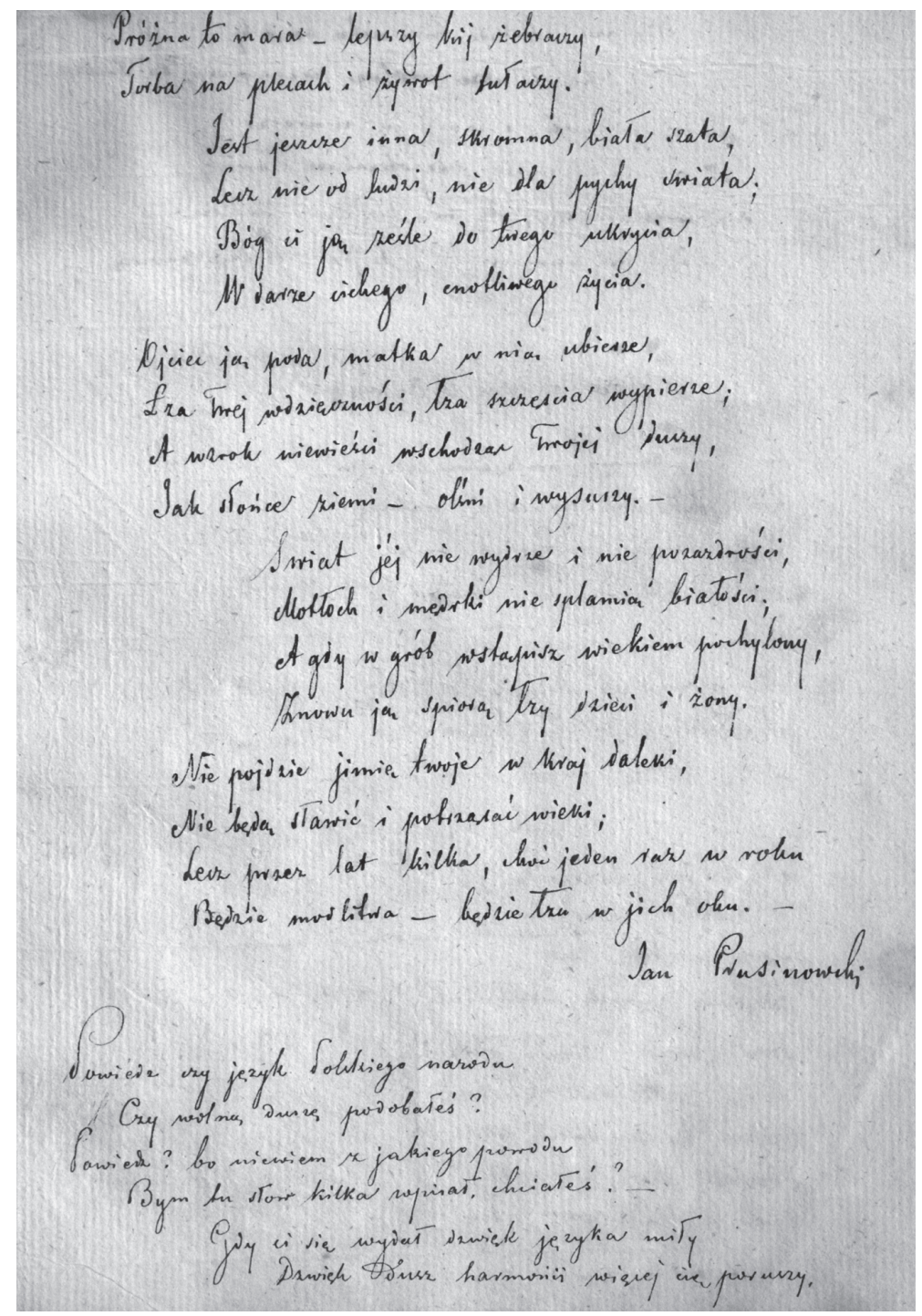

A. Mickiewicz (?), Powiedz..., cz. 1, k. 102 rękopisu 


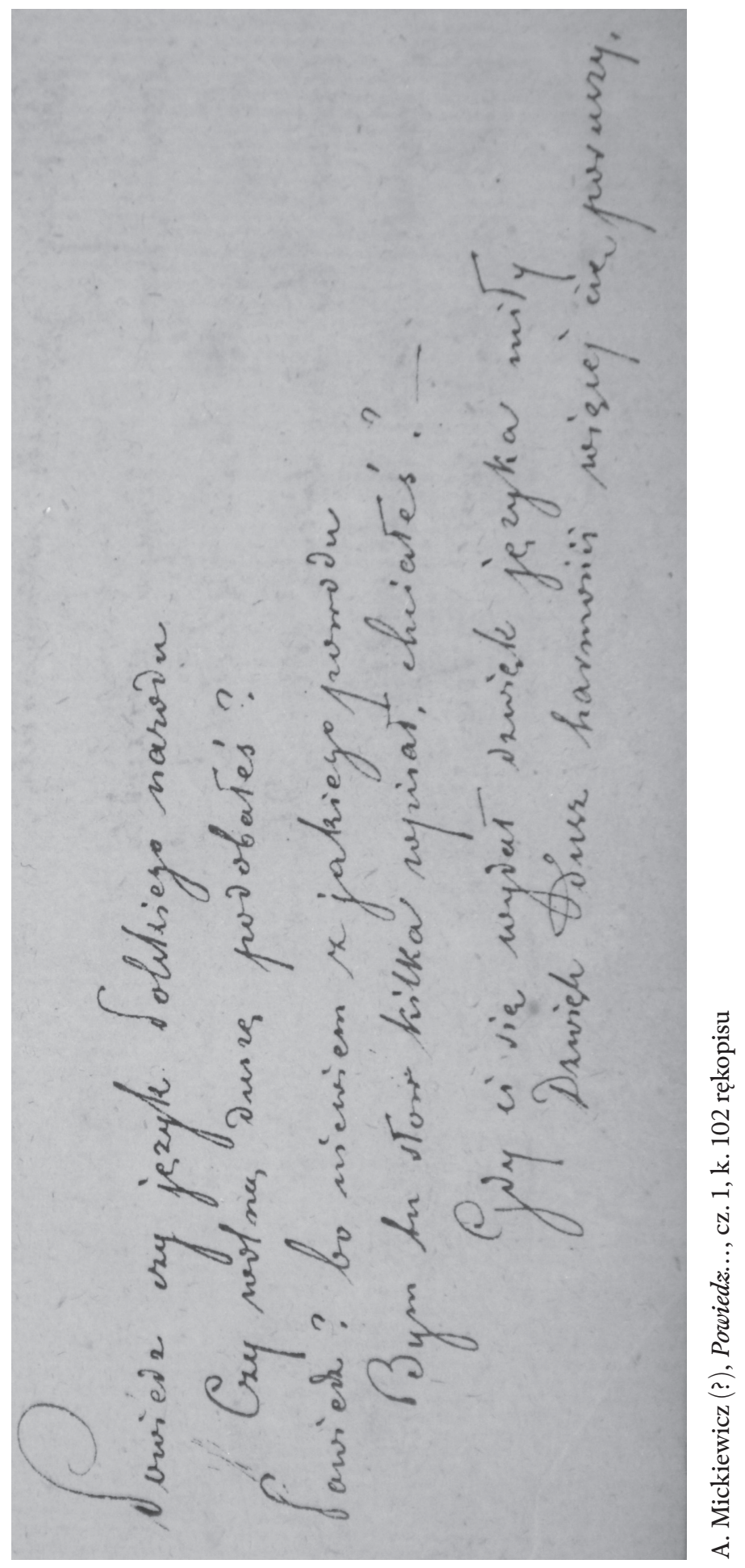




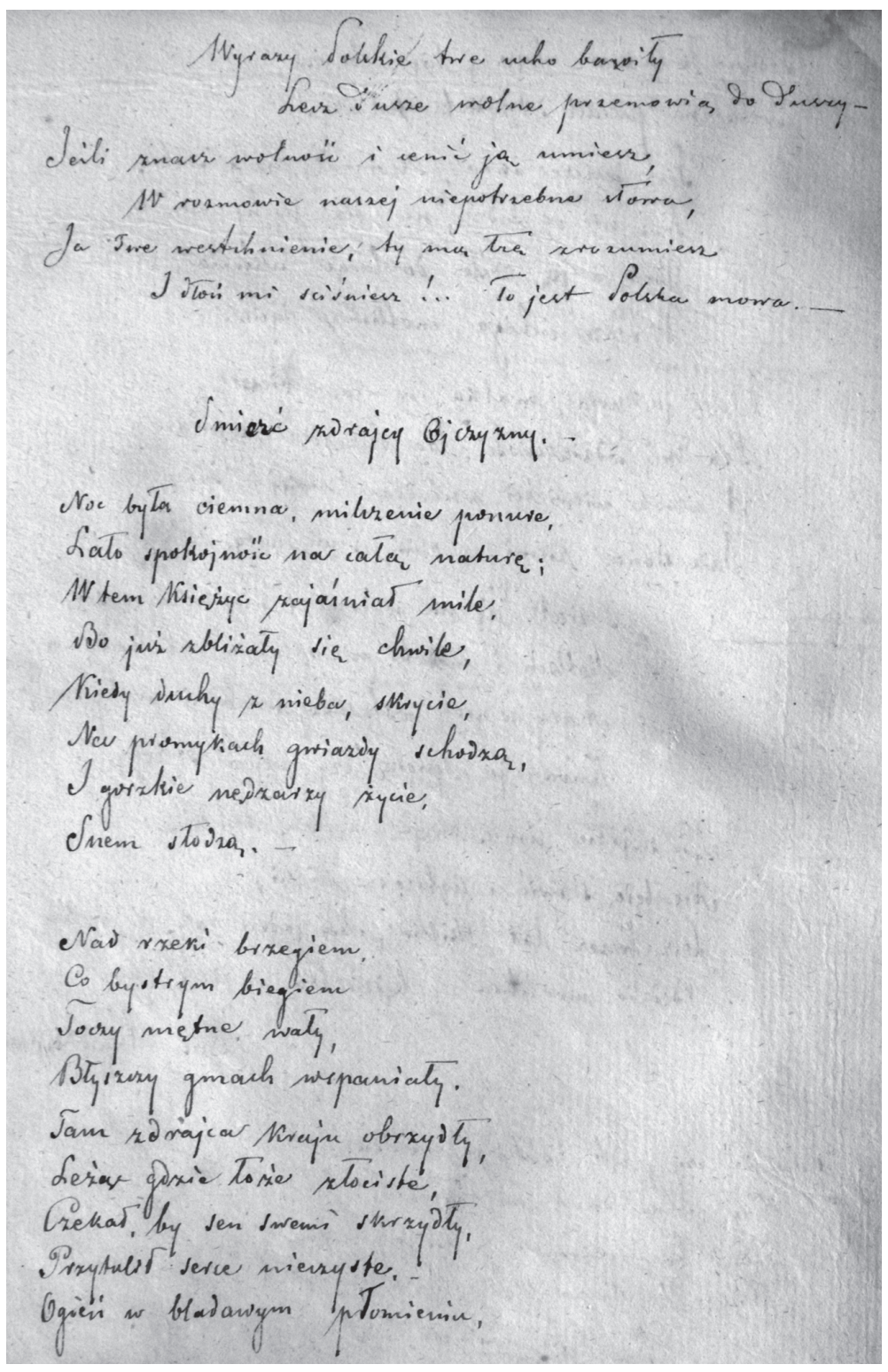

A. Mickiewicz (?), Powiedz..., cz. 2, k. 102v rękopisu 


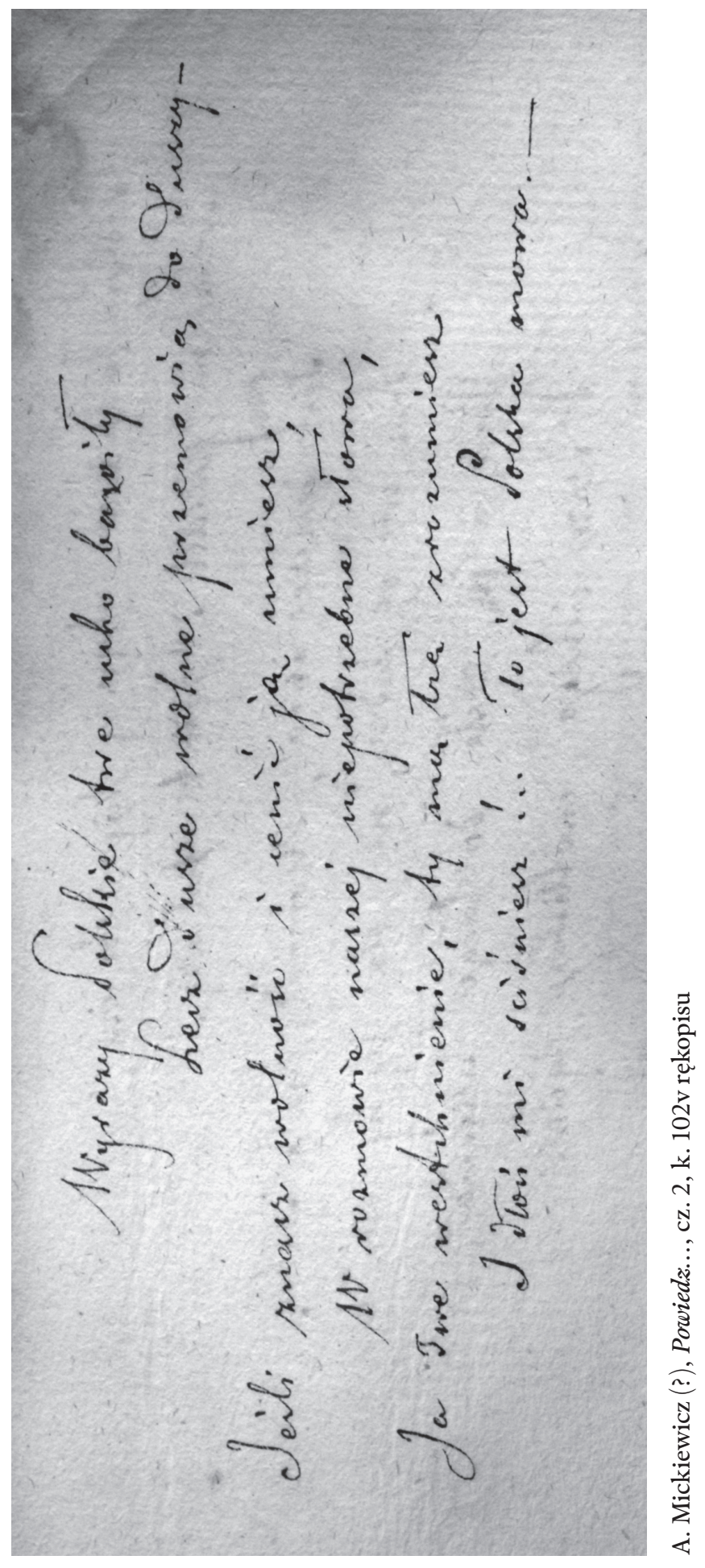




\section{Do Eryna Jachowiera.}

Drieciom, nie noxyotho móniez maj Cryma! Iest peíno smartinien, jest trivions ber likew,

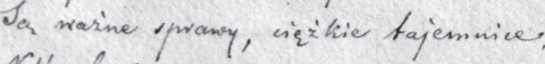

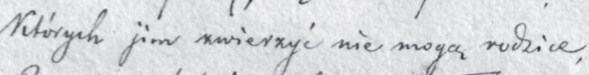
By mie oplatain jich invry mborinthiè, Writhe pothusy. het aleyt goratie imuthi;

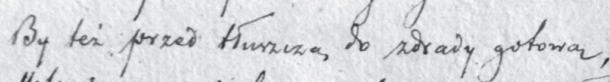

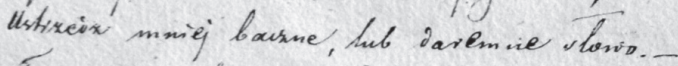
Soz nise : Lobie moj Erytue Srogi dicusiono peeveno, se jestei abogi,

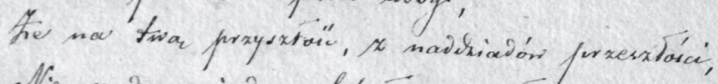

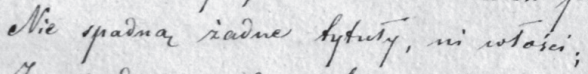

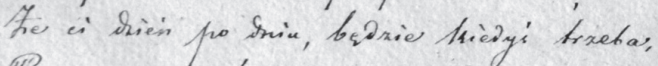

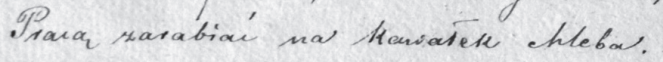
bj: miensiers teme - o tij catej proantie,

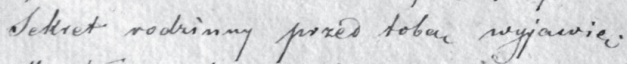

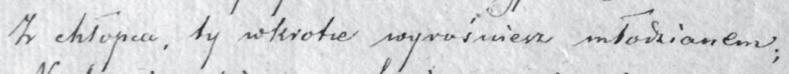

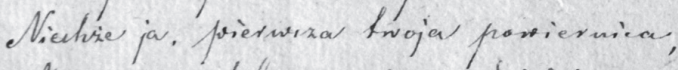

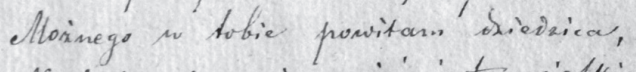

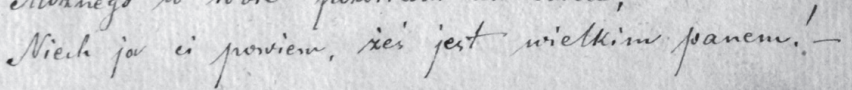

\section{N. Żmichowska, Do Eryka Jachowicza, k. 105 rękopisu}

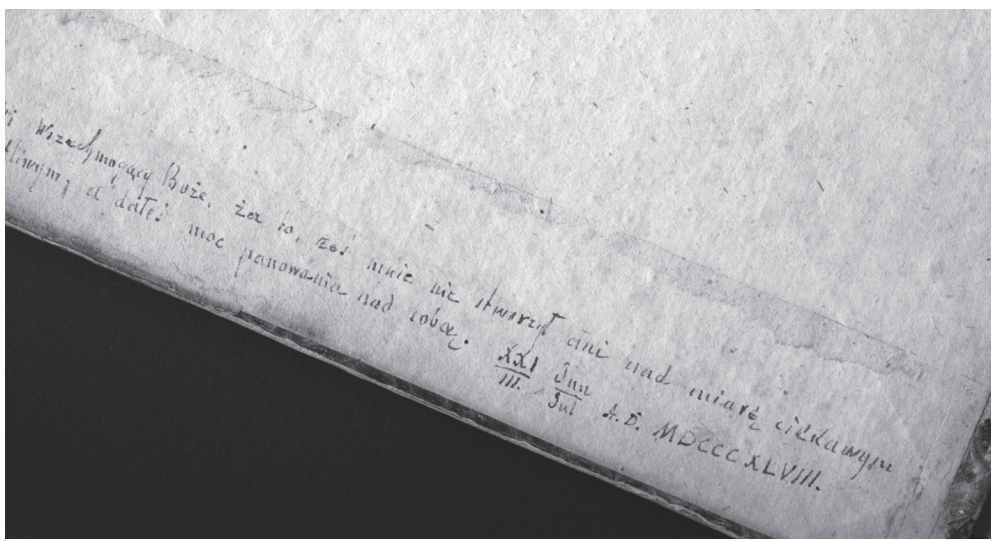

Data na wewnętrznej stronie tylnej okładziny 
JOANNA PIETROWICZ

\section{An unknown poem by Adam Mickiewicz? A manuscript of poetic pieces from the first half of the nineteenth century at the Library of the Poznan Society of Friends of Arts and Sciences. A communiqué.}

The Library of the Poznan Society of Friends of Arts and Sciences has been recently enriched by the accession of the manuscript "Poetical texts from the first half of the nineteenth century". The manuscript includes a number of patriotic poems put down in the manuscript between 1848-1849.

The article provides information on the physical description of the manuscript item (its present shelf number being: rkp. 2112) and a detailed list of its contents. Individual works have been listed in alphabetical order according to the names of the authors, with annotations concerning first editions. The bulk of the poems included in the manuscript were published prior to their inclusion in the manuscript, some of them after the year 1849. At the present stage of the investigation, some of the poems have not been confirmed to have been published earlier. An anonumous 12 -verse poem without a title, attached to the communique at full length, has been identified by the author of the article as a poem whose last four verses were published in 1881 in the book Kraków - Zagrzebiowi under the title W albumie księcia Golicyna by Adam Mickiewicz. The article is intended to stimulate those engaged in research of the history of literature in further investigations concerning the said collection of poems, in particular the last mentioned text.

Joanna Pietrowicz - historyk, kustosz dyplomowany w Dziale Zbiorów Specjalnych Biblioteki Poznańskiego Towarzystwa Przyjaciół Nauk. Zajmuje się katalogowaniem rękopisów, ikonografii i ekslibrisów oraz sprawuje opiekę nad Archiwum PTPN. Zidentyfikowała nieznany list Zygmunta Krasińskiego do Augusta Cieszkowskiego (zob. Z. Przychodniak, Wierzenickie niedyskrecje, Poznań 2006). Obecnie realizowany projekt: „Rękopisy z wielkopolskiego księgozbioru marszałka Andrzeja Opalińskiego (1540-1593)”. Publikowała m.in. w licznych tomach zbiorowych, „Pamiętniku Biblioteki Kórnickiej” oraz w czasopismach regionalnych - „Kronika Wielkopolski”, „Przegląd Wielkopolski”.

e-mail: JPietrowicz@ptpn.poznan.pl 
